\title{
Spiritual Care and Electronic Medical Recording in Dutch Hospitals
}

\author{
Wim Smeets and Anneke de Vries
}

Since the beginning of this century, a growing number of hospitals in the Netherlands have introduced electronic medical recording (EMR) systems. The focus in these systems is on recording medical and nursing data, but quite a few allow for data to be entered from other disciplines, such as spiritual care, as well. Crucially, data recorded in EMR are accessible to others - even if access can be controlled and restricted in various ways.

The use of EMR raises several important questions, which spiritual caregivers have been trying to answer from the start. The present article provides a survey of this discussion as it has been conducted in our country and in which the following issues have predominated: to record or not to record, legal issues, and the "why, what, and how" of recording. Using a case in point, we will illustrate our own recording practices at Radboud University Medical Center (henceforth: Radboudumc). Finally, we will outline some perspectives for the further development of EMR.

\section{To Record or Not to Record?}

On the question of whether or not a spiritual caregiver should use EMR to record patient-related data, we find that some colleagues are vehemently opposed to the whole idea, while others are working on it with enthusiasm. The opponents are typically cultivating a position of non-involvement in the therapeutic process. Elsewhere we have characterized this position as isolationist, outlining its benefits as well as its risks (Smeets, Gribnau and Van der Ven 2011). The main benefit is that it safeguards the "sanctuary" to which each patient is constitutionally entitled; the main risk is

\footnotetext{
W. Smeets $(\triangle) \cdot$ A. de Vries

Radboud University Medical Center, Nijmegen, The Netherlands

e-mail: Wim.Smeets@ radboudumc.nl
} 
spiritual care becoming irrelevant. A related issue here is confidentiality, which we will discuss below. The opponents' principal argument against EMR is that it is incompatible with the confidential nature of spiritual care. They also see it as disproportionally time-consuming.

By contrast, colleagues working with EMR typically take a position of involvement in the therapeutic process, alongside other healthcare professionals. We have characterized this position as assimilatory, with participation in the multidisciplinary therapeutic process as its main benefit and loss of identity as its main risk. From this position, the principal argument in favor of recording is that it may be in the patient's interest to share information with other professionals involved in the therapeutic process (Smeets 2006, 120-144).

\section{Legal Restrictions}

From a legal perspective, the use of EMR generally, and by spiritual caregivers in particular, is not at all unproblematic. Safeguarding the patient's privacy is a central issue in the discussions about EMR and many other such systems in the Netherlands. A project by the Dutch government to develop a nationwide EMR was canceled due to massive resistance from the general public. Tellingly, quite a few doctors, on becoming patients themselves, are reluctant to consent to having their data recorded in EMR. In the Netherlands, the Wet bescherming persoonsgevens (Personal Data Protection Act 2000) has strengthened the patient's legal position, as it stipulates that data provided by the patient remain the patient's property and that the patient has the right to inspect recorded data at any time. Moreover, it is compulsory that the patient unambiguously consent to recording data in an EMR. Healthcare institutions are supposed to provide adequate procedures for this. As of May 2018, the Dutch Personal Data Protection Act has been replaced by the even stricter European General Data Protection Regulation EU 2016/679. This new regulation has a significant impact on the sharing of health-related information. Crucially, the client's explicit consent to documenting personal information about their health or to any other recording of personal data is now compulsory.

The sharing of recorded data is limited in principle to the healthcare professionals involved in a particular patient's therapeutic process. At the moment the Wet beroepen individuele gezondheidszorg (Individual Healthcare Professions Act) grants routine access to recorded data to the practitioners of some professions, but, importantly, not to spiritual care workers. In addition, Article 6 of the Dutch Constitution stipulates that each person has the right to practice his or her worldview, without any interference by others. That is why, traditionally, spiritual ministers have been bound not only to professional confidentiality but to ministerial confidentiality as well. The ministerial confidentiality regulations of the principal churches in the Netherlands are even stricter than most professional confidentiality regulations. Thus, as far as the use of EMR by spiritual caregivers is concerned, their legal status and their ministry would seem to constitute a double impediment 
(Lammers/Smeets 2016). In practice, many EMR systems, including the one that is used at Radboudumc, do allow limited access to spiritual caregivers, legally underpinned by the hospital's legal experts. (It should be noted that patients are typically unaware of all this, assuming that spiritual caregivers are just normal healthcare professionals with normal access to the records.)

\section{Why Use EMR?}

With all the legal and ministerial strings attached to using EMR, why bother to even try? Actually, we think there are some valid reasons, pertaining to the patient's wellbeing, to healthcare generally, and to spiritual care as a profession.

As far as the patient is concerned, one might argue, first, that healthcare is an intrinsically multidisciplinary endeavor. Communication between care providers is essential so as not to confront the patient with fragmentation and contradictions in diagnosis and treatment. Some of this communication has to be in written form, in order to guarantee a reliable transfer of information. Second, the process of recording enables care providers to focus on what the patient needs right now. Third, EMR allows for the planning of the therapeutic process, as it not only records diagnosis and treatment so far but has medical appointment scheduling functionality as well. Fourth, the use of EMR allows the spiritual caregiver to influence the therapeutic process in such a way as to better serve the interests of the patient - even advocating them should they be contrary to those of the therapeutic team - for instance, by drawing attention to aspects of the patient's well-being that have been neglected so far.

As to the therapeutic process generally, one might argue, first, that EMR enhances mutual understanding between care professionals. Based on each other's findings and planning as recorded in the EMR, and through personal or multidisciplinary consultation, they develop a better understanding of each other's disciplines. Second, EMR allows for more efficiency in the therapeutic process, as it reduces overlap and duplications of work. And third, EMR facilitates a better assessment of the effectiveness of the treatments used to cure particular diseases.

Finally, there is an argument in favor of the use of EMR that specifically pertains to spiritual care, viz., that it has a positive effect on the professionalization of spiritual care. It makes us reflect on what we are actually doing and document it in such a way as to be transparent to others, i.e., to professionals from other disciplines as well as to fellow spiritual caregivers. The use of EMR induces the spiritual caregiver to take other professionals' perspectives. Which elements from our conversations with a patient are relevant to and need to be shared with other professionals to ensure good care for that patient, including their spiritual well-being - not only within the present context but in possible follow-up phases as well? Already, our EMR entries have started to play a role in multidisciplinary consultations. Even if long-term effects cannot be assessed as yet, it is our firm impression that other disciplines are beginning to develop a better understanding of the specifics of spiritual care as a profession. In addition, we are confident that the sharing between spiritual 
caregivers of information contained in EMR entries will help us realize a common standard of practice.

\section{What to Record}

There is a broad agreement among spiritual caregivers working with EMR that the data to be recorded in the system should concern the substance of the contacts, typically conversations, between spiritual caregivers and their patients. The basic strategy is to write a more or less condensed account of the conversation. This idiographic approach focuses on the individuality of the patient as a unique person with his or her own unique narrative. The main argument in favor of this approach is that it is the best way of doing justice to the patient as a person. Theoretical backing is provided by narrative approaches in theology, psychology, and, recently, medicine. From a person-centered care perspective, it has also been argued that reading these recorded conversations makes it easier for care providers to relate to individual patients, encouraging them to provide the best care they can.

A second approach has a rather more nomothetic character, as it focuses on similarities and differences between patients, for instance, through a classification of the topics addressed in a particular conversation. In the Netherlands, several classification proposals have been put forward. Some are theory-based, declaring and arranging topics in theoretically defined structures, while others are empirical, working with the topics that are actually raised by patients. An example of a theory-based proposal is the hermeneutic-diagnostic scheme developed by a group of spiritual caregivers in mental healthcare, using work by authors such as Erikson, Nagy, Capps, and Pruijser (Bos et al. 2003).

From a nomothetic-empirical angle, in the 1990s, a group of Roman Catholic healthcare chaplains in the Dutch province of Overijssel came up with a catalogue of 28 topics they found to be regularly addressed in pastoral conversations. The catalogue was used in a survey among all Dutch spiritual caregivers by the Nijmegen Institute of Studies in Empirical Theology, in cooperation with the Netherlands Association of Spiritual Caregivers in Care Institutions, VGVZ. The topics most frequently addressed were sickness, bereavement, life-changing events, relationships, suffering, meaning and appreciation of life, solitude/loneliness, worldview and faith, death, expectations, and the treatment received (Smeets 2009). Recently, a group of spiritual caregivers working in hospitals that use the HiX system have started work on a new catalogue of topics.

One benefit of this topic-based approach is in its user-friendliness. To record a conversation with a patient, the spiritual caregiver only needs to check the topics that have been addressed. In addition, it allows for various types of quantitative research into patient contacts, such as frequency rankings of topics. On the negative side, the selection of topics to be included in the catalogue is inherently problematic. In drawing up such a catalogue, one would typically start with concrete, reallife topics. There should not be too many of these, however, lest the catalogue 
become unmanageable. So the possibility remains of a topic being discussed which is not in the list. A solution to this problem could be to use more abstract "topical groups," as proposed by Van der Ven $(1994,10)$. Based on audio recordings of pastoral conversations, this author came up with ten "topical groups," viz., health, the self, social relations, societal problems, existential questions, religious questions, spiritual questions, moral issues, church-related issues, and pastoral issues. In our Nijmegen CPE training courses, we still use Van der Ven's topical groups in the analysis of pastoral conversations. However, the assignment of a topic to a topical group can still be controversial, and no categorization is everlasting: Who could tell the difference between "church-related issues" and "pastoral issues" nowadays?

The use of rather more formal categories appears to be a viable alternative. At Radboudumc we have drawn inspiration from George Fitchett's work in Assessing Spiritual Needs (2002). His model comprises seven thematic fields to categorize the topics that have been addressed:

- Faith and meaning

- Vocation, values, and responsibilities

- Impactful experiences and emotions

- Courage, hope, and growth

- Rituals and practice

- Community

- Authority and guidance

Dutch society is much more secularized than American society. Topics such as faith, authority, and guidance are not typically addressed in pastoral conversations. That's why we have tried to bring the categories more in line with the topics that do come up; in other words, we have created a more secularized version of Fitchett's model:

- Meaning and sources of inspiration

- Goals in life, values, and responsibilities

- Impactful experiences and emotions

- Courage, hope, and growth

- Rituals and practice

- Community and relationships

"Faith" has been replaced by "sources of inspiration," which may comprise other sources such as music, nature, or science. "Vocation" became "goals in life" - as it is very rare for people to define their work, life, or activities as the response to a vocation. "Community" is no longer exclusively understood as a religious community; but the term can also refer to other types of community, such as a village community, a commune, a group of good friends, or a family. Therefore, the topic "relationships" was added. The notions of "authority," as represented by the church, and "guidance" by a pastor do not occur as topics in our conversations with patients; they have therefore been eliminated. In our experience, the resulting six main topics fit our conversations much better than Fitchett's seven do (see Smeets/de Vries 2016). 
Conveniently, an unlimited number of topics addressed in pastoral conversations can be assigned to this limited number of fields. Also, the model allows spiritual caregivers to identify their favorite areas of religion and/or spirituality, as well as any possible blind spots in their contacts with patients. Third, it communicates to other care providers that spiritual care is not just about religion and ecclesiastical matters but encompasses much broader areas. In our teaching experience, we find that other care providers are typically quite sensitive to this. Fourth, the fields just mentioned coincide with other well-known categorizations in religion and worldview, such as those by Cobb, Glock and Stark, and Smart (Smeets/De Vries 2016). The model thus provides an excellent base for comparative studies on an international scale. Finally, it provides a framework for recording the essential aspects of a patient's narrative as defined above, without recording the narrative as such. It can therefore be seen as a compromise between the idiographic and nomothetic approaches.

\section{Recording at Radboud University Medical Center}

Recording the substance of a conversation with a patient, essential as it may be, is not sufficient for the use of EMR by the spiritual caregiver - which is only modest, when compared to its use by nurses and doctors - to be relevant to the therapeutic process as a whole. What else is needed? Vandenhoeck $(2007,2009)$ has developed an integral recording method, building on the model by the American author A. Lucas, in The Discipline for Pastoral Care Giving. Vandenhoeck's method comprises the following elements:

- Why the contact took place

- Findings

- Interventions

- Results

- Follow-up

In our recording practice, we use this method in combination with our own version of Fitchett's model of spiritual assessment. The "findings" or, as we prefer to call this element, the "brief spiritual impressions," is where the substance of a patient contact is recorded. In our experience, the Fitchett assessment just mentioned is helpful in structuring the findings (see below, first case in point). Vandenhoeck stresses the need for factual recording, containing as few interpretations or other personal notes by the spiritual caregiver as possible. Thus, other care providers can get quick updates on the support by the spiritual caregiver, both on the findings and on the planned follow-up, and take these data into account in their treatment. 


\section{Cases in Point}

At Radboudumc, the Department of Spiritual Care uses the EMR system Epic in the way just outlined, as the following cases in point may illustrate. A spiritual caregiver reports:

One of my colleagues was called in for a baptism ritual on the neonatal ward. A 'spiritual care' order was placed in Epic. On the spiritual care page, my colleague reported: "Conversation this morning with the parents on baptism of X. Baptism took place at 13 hours, with parents and other family members present. The parents were very happy with it." Afterwards this colleague informed me, the order was transferred to me and I went to visit mother and child. I recorded our conversation as follows in Epic (in consultation with the mother).

\section{A. Why the visit took place}

Follow-up contact after baptism ritual, spoke with the mother.

B. Brief spiritual impressions

- Meaning and sources of inspiration: Being together with her child is what inspires Mrs. N. at this moment and what gives meaning to her life.

- Goals in life, values, and responsibilities: Talked about the balance between care for others and care for herself - the latter being as essential as the former.

- Impactful experiences and emotions: Mrs. N. would very much like to be in agreement with her husband with respect to the continuation of the treatment. She feels a tension.

- Courage, hope, and growth: The mother is cherishing hopes about the medical treatment of her child.

- Rituals and practice: Both parents have experienced the baptism ritual as supportive in a difficult moment.

- Community: Mrs. N. needs to be at home from time to time, in order to be in touch with her loved ones.

C. Interventions

Mainly been attentively listening to what Mrs. N. had to say.

D. Results

Mrs. N. had a sense of relief after the conversation.

E. Follow-up

Talked about possible further counseling, involving husband as well. 


\section{F. (Multidisciplinary) referral-primary/secondary care}

Not applicable.

The referral category is not in Vandenhoeck's recording method. We added it with a view to our potential involvement in transmural care, specifically in providing spiritual care in the patient's home environment.

Notwithstanding all the modeling and structuring behind EMR, there is still considerable freedom when it comes to the actual recording of our conversations. Here is an example of a rather more succinct entry:

A. Why the visit took place

Patient had asked for a visit.

\section{B. Brief spiritual impressions}

Patient is emotionally tired and sad.

\section{Interventions}

Have listened to her experiences and sorrow and talked with her about end-oflife issues.

\section{Results}

Patient feels being heard, sense of relief.

\section{E. Follow-up}

Promised to visit her again Wednesday next week.

The perfect way to record data on patient contacts still needs to be worked out. On the one hand, the wording should be concise, as in the above examples, both to enable other care providers to quickly examine the records and to protect the patient's privacy. On the other hand, brevity carries a risk of misinterpretation, and the patient's individual narrative should not be obscured. Consultations within our team on this subject take place regularly and are likely to continue for some time.

\section{Perspectives}

In this contribution we have discussed our own use of EMR as implemented at Radboudumc, i.e., a system containing one spiritual care "page," which is accessible to all care providers involved in the therapeutic process. However, alternative setups are conceivable - each of them giving rise to their own legal, moral, and practical questions - such as having two pages, one accessible to all and the other 
with access limited to fellow spiritual caregivers, allowing more sensitive data to be recorded. Another option might be the inclusion of data from the realm of spiritual care in other care providers' pages. Also, in addition to EMR for hospital care, one might wish to have a system for outpatient care. At Radboudumc, some of these variants are already being worked on and we plan to report on them in due course. As mentioned already, the best way of recording data (in terms of wording) still needs to be worked out, possibly in consultation with patients and/or relatives as "producers" of the data and with the other care providers as "consumers."

\section{Finally}

Digital recording of spiritual care remains a contested issue in the Netherlands. At Radboudumc we feel that, on balance, the use of EMR in spiritual care is to be welcomed, as it serves several interests. It is in patients' interest that their concerns are remembered and taken into account beyond the conversation with the spiritual caregiver. It is in the other caregivers' interest to know the contribution of spiritual care and to integrate it into the therapeutic processes we are all working on together. Through EMR, healthcare managers can obtain a clear picture of what meaning and spirituality, as components of integral care, really entail. Finally, EMR helps spiritual caregivers to account for what they are doing and to study and improve their own practices. To ensure a stable future for our profession in healthcare, EMR seems, in our view, indispensable. 


\title{
Commentary
}

\author{
David Neuhold $(\bowtie)$ \\ University of Zurich, Zurich, Switzerland \\ e-mail: david.neuhold@unifr.ch
}

\section{Basic Reflections on Documentation}

In their contribution, Smeets and De Vries provide a range of arguments to the effect that spiritual care workers should be involved in the documentation process and thus actively participate in EMR ("electronic medical records"). Nevertheless, they do not denigrate skeptical or even opposing positions. Rather, they think that there is a lot to be gained from listening to such critical voices. However, these "isolationist" voices, as Smeets and de Vries call them, are becoming quieter and quieter. The discussion of the article at our workshop at the beginning of 2019 confirmed this. There is also a generational gap. "Isolationist" voices often tend to be those of elder spiritual care workers.

According to Smeets and de Vries, it is important first and foremost that documentation does not become an end in itself: it should only be a means to an end. Secondly, documentation should not be excessively time-consuming (as it has already become in the Netherlands, and probably not only there). And thirdly, the written word cannot become a substitute for everyday interprofessional (oral) communication in the clinical context. As already clearly demonstrated in the book by Wim Smeets (Spiritual Care in a Hospital Setting: An Empirical-Theological Exploration from 2006), the author has an impressive knowledge of a number of concrete contexts. Great importance is attached to empirical investigation and to everyday conditions.

\section{Importance of the "Narrative Approach"}

An "idiographic approach focuses on the individuality of the patient as a unique person with his or her own unique narrative," Smeets and De Vries note in their contribution. From such approaches to documentation they distinguish nomothetical approaches. These focus more on general, prefabricated classifications. Indicators in such nomothetical approaches can be determined on the one hand through theory and on the other through empirical research. Smeets and De Vries prefer a narrative, idiographic approach to documentation, but see a workable compromise in empirically supported indicators for documentation systems. However, narrative documentation patterns are also problematic in many respects, at least for some authors. Many questions arise: Are the narratives understandable for others? Do they make sense to the members of an interprofessional team? Don't they pose a danger to pastoral confidentiality? After all, don't narrative entries take a lot of time? In addition, do they really benefit the patient? Especially for interprofessional documentation in EMR, a standardized documentation format has many advantages, although it undoubtedly submits itself to a certain institutional logic. On the other hand, the use of standardized formats creates a new opportunity for cooperation in the design of the formats and may facilitate further cooperation, provided that hospitals and healthcare facilities have an open ear. The further integration of spiritual care does not only depend on the spiritual care givers themselves but essentially on the appraisals and judgments made by others, that is, spiritual care providers are dependent on the willingness of other parties to include them in the patient's care. They need medical and other hospital professionals to approve of what they are doing.

\section{The Pastor-Patient Relationship and Pastoral Confidentiality}

Pastoral confidentiality is a crucial point in many debates on documentation. Repeatedly it has been the subject of discussion. Often the issue is raised by actors who are themselves 
hostile to documentation. It is important to emphasize that the patient is the bearer of (t)his secret, not the pastor or chaplain. Moreover, there are wide areas of interpersonal communication that do not fall under the scope of pastoral confidentiality. The recording of many encounters is therefore unproblematic. In addition, it is possible to maintain professional secrecy within a team. However, the field is undisputedly delicate; and it is particularly delicate in narrative documentation processes. The case study Smeets and De Vries mention in the main text therefore merits more close examination. The use of documentation in this case may or may not be illegal, but it is certainly morally questionable. For the entry appears to suggest family dissonance. Has the mother of the sick child given her consent to this entry? If not, then I would consider such a narrative entry problematic.

What comes into play in this case - apart from pastoral confidentiality - is the relationship between pastor and patient. In the discussion of his contribution to our workshop, Smeets showed particularly clearly how this relationship can lead to differences in perception. There are divergences. Spiritual care givers often see themselves in a different role than patients do. Intensive empirical research is needed in this area, as Smeets points out. Such research will be easier with spiritual care documentation as a resource. I would like to add that PROMs ("patient reported outcome measures"), that is, feedback created by patients, could be an especially meaningful addition to this field of research. It is undisputed that research work in this area has enormous potential. These considerations really affect the core of patient-oriented care and concern in the hospital context. As many studies have shown in detail, spiritual care givers do not need to have any worries: Their contribution in the clinical context is highly appreciated by patients.

\section{References}

Bos, T., A. Kemper, P. Van der Schaft, and A. Van 't Spijker-Niemi. 2003. Een hermeneutischdiagnostisch model voor geestelijke verzorging. Tijdschrift Geestelijke Verzorging 6 (27): 23-39.

Fitchett, G. 2002. Assessing spiritual needs. A guide for caregivers. Minnesota: Augsberg.

Lammers, H., and W. Smeets. 2016. De positie van de geestelijk verzorger in juridisch perspectief. In Handboek spiritualiteit in de palliatieve zorg, ed. W. Smeets et al., 66-87. Almere: Parthenon.

Smeets, W. 2006. Spiritual Care in a Hospital Setting. An empirical-theological exploration. Leiden: Brill.

. 2009. Gender en lichamelijkheid in de beleving van geestelijk verzorgers. Tijdschrift Geestelijke Verzorging 13 (59): 14-27.

Smeets, W., and A. de Vries. 2016. Spiritual screening in a secular context. In Compassion for one another in the Global Village. Social and cultural approaches to care and counselling, ed. U. Elsdörfer and T.D. Ito, 92-99. Wien: LIT.

Smeets, W., F.W.J. Gribnau, and J.A. van der Ven. 2011. Quality assurance and spiritual care. Journal of Empirical Theology 24 (1): 80-121.

van der Ven, J.A. 1994. Pastorale protocolanalyse II. Pastoraat in maat en getal. Praktische Theologie 21 (1): 7-20.

Vandenhoeck, A. 2007. De meertaligheid van de pastor in de gezondheidszorg. Resultaatgericht pastoraat in dialoog met het narratief-hermeneutisch model van C.V. Gerkin. Leuven: Katholieke Universiteit.

. 2009. Op de kaart! Registratie vanuit pastoraal perspectief. Pastorale Perspectieven 143: 6-16. 
Open Access This chapter is licensed under the terms of the Creative Commons Attribution 4.0 International License (http://creativecommons.org/licenses/by/4.0/), which permits use, sharing, adaptation, distribution and reproduction in any medium or format, as long as you give appropriate credit to the original author(s) and the source, provide a link to the Creative Commons license and indicate if changes were made.

The images or other third party material in this chapter are included in the chapter's Creative Commons license, unless indicated otherwise in a credit line to the material. If material is not included in the chapter's Creative Commons license and your intended use is not permitted by statutory regulation or exceeds the permitted use, you will need to obtain permission directly from the copyright holder.

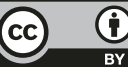

